\title{
Reducing Hospitalization for Long Stay Patients
}

\author{
Mary Luziani' ${ }^{1}$, Ronald Lagoe ${ }^{2 *}$, Shelly Littau ${ }^{2}$ \\ ${ }^{1}$ St. Joseph's Hospital Health Center, Syracuse, NY, USA \\ ${ }^{2}$ Hospital Executive Council, Syracuse, NY, USA \\ Email: ^Hospexcl@cnymail.com
}

How to cite this paper: Luziani, M., Lagoe, R. and Littau, S. (2017) Reducing Hospitalization for Long Stay Patients. Case Reports in Clinical Medicine, 6, 221-226. https://doi.org/10.4236/crcm.2017.68023

Received: July 6, 2017

Accepted: August 5, 2017

Published: August 9, 2017

Copyright $\odot 2017$ by authors and Scientific Research Publishing Inc. This work is licensed under the Creative Commons Attribution International License (CC BY 4.0).

http://creativecommons.org/licenses/by/4.0/

\begin{abstract}
This case study described the structure and preliminary impact of a hospital program to improve efficiency by reducing long stays for adult medicine inpatients. The program focused resources on these patients, including an experienced case management staff, effective relationships with long term care providers, and Subacute and Complex Care services. The program caused the total number of adult medicine patient days associated with these patients to decline by 1593 , or 4780 on an annual basis.
\end{abstract}

\section{Keywords}

Hospitals, Hospital Lengths of Stay, Long Term Care

\section{Introduction}

In the United States, increased interest is focusing on reducing health care costs by improving efficiency. The implementation of the Prospective Payment System in 1983 was probably the most important influence on the efficiency of care during the past several decades. This system, based on payments per discharge, resulted in the elimination of substantial volumes of unnecessary patient days in United States hospitals [1] [2] [3] [4].

Providers of health care, such as acute hospitals, need to operate efficiently because extended stays can result in large additional expenditures for labor, room and board, pharmaceuticals, and other costs. Extended stays also create opportunities for post admission complications [3] [5] [6].

Perhaps the most challenging aspect of hospital length of stay reduction involves long stay patients. These patients frequently experience high severity of illness related to medical and surgical diagnoses. They often remain in hospitals for extended periods because of the need for long term care services including home health care and nursing homes. Efforts to address these lengths of stay 
have been supported by Medicare Bundling Programs [7] [8].

Increased attention concerning patients experiencing long stays has also focused on those who need complex care services for extended periods. In many communities these services, such as intravenous antibiotics, extended would care, and bariatric care, are not available outside acute hospitals [9] [10] [11].

\section{Population and Method}

This case study described the development and implementation of a program to reduce long hospital stays for adult medicine inpatients in St. Joseph's Hospital Health Center in Syracuse, New York. This hospital had 25,532 discharges excluding well newborns in 2014, 24,808 discharges in 2015, and 25,101 discharges in 2016. It had the highest number of adult medical and surgical discharges in the surrounding region.

Historically, St. Joseph's Hospital Health Center has worked with area nursing homes to reduce inpatient lengths of stay. It was the only area hospital to participate in Medicare's Bundled Care for Improvement Program. The hospital has also worked with other area hospitals to reduce lengths of stay through the Hospital Executive Council. St. Joseph's Hospital Heath Center worked with the Hospital Executive Council to develop this study. The Council coordinates programs concerning efforts to address long stay hospital patients among the Syracuse hospitals.

Like many acute care hospitals, St. Joseph's Hospital Health Center experienced substantial reductions in inpatient stays in the decades after implementation of reimbursement by discharges by Medicare, Medicaid, and insurance payers. In recent years, those reductions have plateaued. More recently, the Hospital initiated additional inpatient length of stay reduction efforts. These initiatives reduced stays for many patients but did not have a sustained impact on those with the longest stays. These patients were associated with most of the remaining excess patient days.

In response to this need, a new series of programs focusing on long stay patients was initiated early in 2017. These programs included components designed to address this specific population.

A cornerstone of the new programs was the use of dedicated, experienced R.N. Care Managers. These individuals have extensive clinical experience with long stay patients that allowed them to plan effectively for the care needs of these individuals after discharge. These Care Managers are required to be active, creative, and focused in developing patient discharge plans. They have strong relationships with providers of care in the community. They have used these relationships to broker admissions to these services.

The programs also included the implementation of specific care management mechanisms. A case management presence was developed in the hospital including the Emergency Department at least 12 hours per day. Expected lengths of stay were identified within 24 hours of admission for each inpatient. They 
were made visible on Electronic Bed Boards and Electronic Medical Records.

With respect to Case Management within St. Joseph's Hospital Health Center, the new programs also included daily (7 days per week) unit based multidisciplinary meetings to discuss expected lengths of stay, expected dates of discharge, barriers to patient progression, and assignment of accountability for mitigation of barriers to discharge for each inpatient. It also included daily (7 days per week) escalation meetings for Care Managers to bring unresolved barriers to hospital senior leaders for additional support and resolution.

Another component of the program was physician engagement and collaboration. This included strong physician champions and involvement in process improvement activities related to patient progression.

These activities within the hospital developed a culture emphasizing reduction of stay. This included a "Think Home First" attitude, supporting patient interests in discharge home and avoiding delays sometimes associated with long term care placements.

Another major component of the new programs was their relationship with long term care services. This involved strengthening patient referral relationships with the Hospital's Certified Home Health Care Program. It also involved further development of relationships with area skilled nursing facilities. This process was accomplished through the establishment of a narrow network of preferred long term care providers. In order to participate in this network, skilled nursing facilities were expected to accept admissions from the hospital 7 days per week and meet additional outcomes objectives.

The new programs addressing the needs of potential long stay patients at St. Joseph's Hospital Health Center also included Subacute and Complex Care services. A number of these programs had been developed with local skilled nursing facilities and the other Syracuse hospitals through the Hospital Executive Council.

In February 2017, a new group of Complex Care programs was developed by St. Joseph's Hospital Health Center and the Hospital Executive Council. These programs focused on reducing long stays produced by patients receiving extended medication therapy. The program involved discharging these patients home with complex care therapies where possible. Where home discharges were not possible, the program involved completion of intravenous and other medication therapies in participating area nursing homes.

In order to support the Subacute and Complex Care Programs, the hospital staff engaged the pharmacy to identify potential patients early in their stays. These patients were reviewed at daily escalation meetings in order to review their potential for discharge when medically stable.

In this case study, the St. Joseph's Hospital Health Center programs for reduction of inpatient stays were evaluated for the four months after their implementation, February-May 2017, in comparison with the same periods in 2015 and 2016. This evaluation included numbers of patients with long stays and utilization for discharges to long term care services. The analysis was developed using 
basic descriptive statistics.

\section{Results}

The data concerning long patient stays were based on numbers of adult medicine patients who stayed longer than 20 days between February-May 2015 and February-May 2017. The number of patients with stays longer than 20 days at the hospital declined from 84 during February-May 2015 to 32 during the same period in 2017, a reduction of 62 percent. During the same interval, the number of adult medicine patients with an infectious disease as a principal diagnosis who stayed longer than 20 days declined from 35 to 14 . Although preliminary, these data suggested that numbers of long stay patients have declined substantially.

The case study also included utilization data for adult medicine, the largest inpatient service at St. Joseph's Hospital Health Center, during the initial months of the new programs. This information was based on comparisons of discharges and lengths of stay for discharges to home health care and nursing homes, the sources of most long stay patients, between February-May 2015 and 2017. This information follows in Table 1.

This information demonstrated that numbers of adult medicine patients discharged to long term care shifted toward home and lower levels of care during the initial months of the new programs. This shift was associated with reduced lengths of stay for patients requiring long term care.

The number of discharges to nursing homes declined by 135 between February-May 2015 and 2017. During the same period, the number of discharges to home health care increased by 428 .

Table 1. Inpatient adult medicine mean lengths of stay, St. Joseph's Hospital Health Center, February-May 2015-2017.

\begin{tabular}{ccccccccc}
\hline & \multicolumn{3}{c}{$\begin{array}{c}\text { Number of } \\
\text { Discharges }\end{array}$} & \multicolumn{2}{c}{$\begin{array}{c}\text { Mean Length } \\
\text { of Stay }\end{array}$} & $\begin{array}{c}\text { Length of Stay } \\
\text { Difference }\end{array}$ & $\begin{array}{c}\text { Patient Days } \\
\text { Difference }\end{array}$ \\
\hline & 2015 & 2016 & 2017 & 2015 & 2016 & 2017 & $2015-2017$ & $2015-2017$ \\
\hline Home Care & & & & & & & & \\
February & 184 & 213 & 283 & 6.46 & 5.43 & 4.98 & -1.48 & -272.32 \\
March & 164 & 248 & 284 & 6.82 & 5.49 & 5.34 & -1.48 & -242.72 \\
April & 153 & 191 & 255 & 6.33 & 5.97 & 4.89 & -1.44 & -220.32 \\
May & 167 & 221 & 274 & 6.21 & 4.51 & 4.83 & -1.38 & -230.46 \\
Nursing Home & & & & & & & & -145.80 \\
February & 180 & 176 & 175 & 7.69 & 7.79 & 6.88 & -0.81 & -202.65 \\
March & 193 & 187 & 177 & 7.70 & 6.73 & 6.65 & -1.05 & -69.89 \\
April & 241 & 214 & 128 & 7.33 & 6.72 & 7.04 & -0.29 & -209.44 \\
May & 154 & 156 & 153 & 7.88 & 6.97 & 6.52 & -1.36 & \\
\hline
\end{tabular}

Patient days differences based on 2015 discharges to home care and nursing homes. Adult medicine data exclude Diagnosis Related Groups concerning surgery, obstetrics, pediatrics, psychiatry, alcohol/substance abuse treatment, rehabilitation, and all patients aged 0 - 17 years. Source: Hospital Executive Council. 
At the same time, the case study data demonstrated that stays for discharges to home health care declined by 1.48 days in February, 1.48 days in March, by 1.44 days in April, and 1.38 days in May between 2015 and 2017. These declines occurred despite an increase in volume largely generated by patients previously discharged to nursing homes. They caused the total number of patient days associated with discharges to home care to decline by 965 between February - May 2015 and 2017, based on 2015 discharges.

Stays for discharges to nursing homes declined by 0.81 days in February, 1.05 days in March, 0.29 days in April, and 1.36 days in May. These changes occurred despite the fact that the severity of illness of this population increased as some patients were referred to home health care. These changes caused the number of patient days associated with discharges to nursing homes to decline by 627 between February-May 2015 and 2017 based on 2015 discharges.

\section{Discussion}

This case study summarized the structure and preliminary impact of a hospital program supporting increased efficiency by reducing the longest inpatient stays. These stays have been a major barrier to the development of increased health care efficiency in the United States.

The St. Joseph's Hospital Health Center program focused a number of resources on potential long stay patients in order to achieve this objective. The most important of these were an experienced case management staff, specific procedures within the hospital, and effective relationships with long term care providers in the community. They also included the development of new Subacute and Complex Care services through partnerships with providers in the community.

These programs caused the total number of patient days associated with discharges to home health care and nursing homes to decline by 1593 during a four month period during the initial implementation of the programs. On an annual basis, this would result in a decline of 4780 patient days.

As populations age and care requirements increase, the needs of patients with long stays will continue to challenge health care providers. Additional case studies should focus on programs developed to meet these challenges.

\section{References}

[1] Dentzler, S. (2011) Urgent Measures for an Old Problem. Health Affairs, 30, 1626.

[2] Friedman, B., De La Mare, J., Andrews, R. and McKenzie, D.H. (2002) Practical Options for Estimating the Costs of Hospital Stays. Journal of Health Care Finance, 29, 1-13.

[3] Cushing, W.T. (2004) Extra Hospital Days Can Cost You Plenty. Medical Economics, 81, 83 .

[4] Shah, B.R., Reed, S.D., Francis, J., Ridley, D.B. and Schulman, K.A. (2003) The Cost of Inefficiency in U.S. Hospitals 1985-1987. Journal of Health Care Finance, 30, 1-9.

[5] Pena, A.D. and Ndieyea, M. (2002) Developing Hospital Efficiency Control Meas- 
ures. World Hospitals and Health Services, 38, 2-9, 41-43.

[6] Skinner, J., Chandra, A., Goodman, D. and Fisher, E.S. (2009) The Elusive Connection Between Health Care Spending and Quality. Health Affairs, 28, w119-w123. https://doi.org/10.1377/hlthaff.28.1.w119

[7] Marek, K.D. and Rantz, M.J. (2000) Aging in Place: A New Model for Long Term Care. Nursing Administration Quarterly, 24, 1-11. https://doi.org/10.1097/00006216-200004000-00003

[8] Whitman, E. (2016) Bundled Payment Expansion Brings Providers More Risk and Opportunity. Modern Healthcare, 46, 8-10.

[9] Gawande, A.A. (2011) The Hot Spotters: Can We Lower Costs By Giving the Neediest Patients Better Care? New Yorker.

[10] Hong, C.S., Siegel, A.L. and Ferris, T.G. (2014) Caring for High Need, High Cost Patients: What Makes for a Successful Care Management Program? Commonwealth Fund, New York.

[11] Johnson, T.L., Rinehart, D.J., Durfee, J., Brewer, D., Batal, H., Blum, J., Oronce, C.J. and Melinkovich, P. (2015) For Many Patients Who Use Large Amounts of Health Services, the Need is Intense Yet Temporary. Health Affairs, 34, 1312-1323. https://doi.org/10.1377/hlthaff.2014.1186

Submit or recommend next manuscript to SCIRP and we will provide best service for you:

Accepting pre-submission inquiries through Email, Facebook, LinkedIn, Twitter, etc. A wide selection of journals (inclusive of 9 subjects, more than 200 journals) Providing 24-hour high-quality service User-friendly online submission system Fair and swift peer-review system Efficient typesetting and proofreading procedure Display of the result of downloads and visits, as well as the number of cited articles Maximum dissemination of your research work

Submit your manuscript at: http://papersubmission.scirp.org/ Or contact crcm@scirp.org 